Article

\title{
Prey Lysate Enhances Growth and Toxin Production in an Isolate of Dinophysis acuminata
}

\author{
Han Gao ${ }^{1,2}$, Mengmeng Tong ${ }^{2, *}$, Xinlong An ${ }^{3}$ and Juliette L. Smith ${ }^{1}$ \\ 1 Virginia Institute of Marine Science, College of William \& Mary, Gloucester Point, VA 23062, USA; \\ gghanbing@zju.edu.cn (H.G.); jlsmith@vims.edu (J.L.S.) \\ 2 Ocean College, Zhejiang University, Zhoushan 316000, China \\ 3 Ocean College, Agricultural University of Hebei, Qinhuangdao 066000, China; axlqhd@126.com \\ * Correspondence: mengmengtong@zju.edu.cn; Tel.: +86-188-5816-0402
}

Received: 22 November 2018; Accepted: 14 January 2019; Published: 21 January 2019

\begin{abstract}
The physiological and toxicological characteristics of Dinophysis acuminata have been increasingly studied in an attempt to better understand and predict diarrhetic shellfish poisoning (DSP) events worldwide. Recent work has identified prey quantity, organic nitrogen, and ammonium as likely contributors to increased Dinophysis growth rates and/or toxicity. Further research is now needed to better understand the interplay between these factors, for example, how inorganic and organic compounds interact with prey and a variety of Dinophysis species and/or strains. In this study, the exudate of ciliate prey and cryptophytes were investigated for an ability to support $D$. acuminata growth and toxin production in the presence and absence of prey, i.e., during mixotrophic and phototrophic growth respectively. A series of culturing experiments demonstrated that the addition of ciliate lysate led to faster dinoflagellate growth rates $(0.25 \pm 0.002 / \mathrm{d})$ in predator-prey co-incubations than in treatments containing (1) similar levels of prey but without lysate $(0.21 \pm 0.003 / \mathrm{d}),(2)$ ciliate lysate but no live prey $(0.12 \pm 0.004 / \mathrm{d})$, or (3) monocultures of $D$. acuminata without ciliate lysate or live prey $(0.01 \pm 0.007 / \mathrm{d})$. The addition of ciliate lysate to co-incubations also resulted in maximum toxin quotas and extracellular concentrations of okadaic acid (OA, $0.11 \pm 0.01 \mathrm{pg} / \mathrm{cell}$; $1.37 \pm 0.10 \mathrm{ng} / \mathrm{mL}$ ) and dinophysistoxin-1 (DTX1, $0.20 \pm 0.02 \mathrm{pg} /$ cell; $1.27 \pm 0.10 \mathrm{ng} / \mathrm{mL}$ ), and significantly greater total DSP toxin concentrations (intracellular + extracellular). Pectenotoxin-2 values, intracellular or extracellular, did not show a clear trend across the treatments. The addition of cryptophyte lysate or whole cells, however, did not support dinoflagellate cell division. Together these data demonstrate that while certain growth was observed when only lysate was added, the benefits to Dinophysis were maximized when ciliate lysate was added with the ciliate inoculum (i.e., during mixotrophic growth). Extrapolating to the field, these culturing studies suggest that the presence of ciliate exudate during co-occurring dinoflagellate-ciliate blooms may indirectly and directly exacerbate $D$. acuminata abundance and toxigenicity. More research is required, however, to understand what direct or indirect mechanisms control the predator-prey dynamic and what component(s) of ciliate lysate are being utilized by the dinoflagellate or other organisms (e.g., ciliate or bacteria) in the culture if predictive capabilities are to be developed and management strategies created.
\end{abstract}

Keywords: Dinophysis acuminata; Mesodinium rubrum; lysate; organic matter; diarrhetic shellfish poisoning; okadaic acid; dinophysistoxin; pectenotoxins

Key Contribution: The addition of ciliate lysate, but not cryptophyte lysate, to co-incubations led to increased Dinophysis growth rate and biomass, maximum DSP toxin quotas and extracellular toxin concentrations, and significantly greater total DSP toxins. 


\section{Introduction}

The dinoflagellate Dinophysis spp. has been associated with diarrhetic shellfish poisoning (DSP) events worldwide due to human exposure to the toxin okadaic acid (OA) and its derivatives, dinophysistoxins (DTXs) [1,2]. These lipophilic compounds can accumulate in filter-feeding bivalves and adversely affect humans and other animal consumers. As strong inhibitors of serine and threonine protein phosphatases, DSP toxins can promote potent tumors [3], induce intestinal distress such as vomiting and diarrhea [2,4], and limit the growth of phytoplankton competitors [5,6]. Many toxigenic Dinophysis spp. also synthesize pectenotoxins (PTXs), a class of bioactive, polyether lactones. While not a contributor to DSP, some pectenotoxins are acutely toxic to vertebrate models via intraperitoneal injection [7,8], and therefore, the toxin class is regulated in the European Union [9].

With the threat of DSP appearing to be on a rise globally and emerging in new regions, e.g., U.S. coastlines, investigations into the possible drivers of Dinophysis spp. growth and toxin production have become a growing area of research in the last decade. This important work was made possible through the revolutionary discovery by Park et al. [10]: to grow in culture, Dinophysis spp. must be fed ciliates, Mesodinium rubrum, that previously grazed upon cryptophytes of the Teleaulax/Geminigera clade [11]. Molecular evidence supports the need for this multi-stage culturing scheme, as Dinophysis and Mesodinium plastids have been shown to originate from cryptophytes [12-16] and Dinophysis cells have been found in the field to concurrently contain plastids originating from different strains of cryptophyte [17]. More specifically, ciliates of the genus Mesodinium capture, sequester, and regulate the nuclear genome of its cryptophyte prey $[11,15,16]$, after which, Dinophysis consumes the plastids in the ciliates by kleptoplasty via a peduncle. Stemming from this advancement in culturing, numerous D. acuminata isolates [10,18-26] and isolates of other Dinophysis spp. [21,27-31] have been successfully established, allowing now for comparisons between geographical strains and species.

Prior to the multi-stage culturing technique put forth by Park et al. [10], however, multiple types of organic material, in both dissolved and particulate form, were trialed in an attempt to culture Dinophysis as a monoculture, including dissolved organic materials (soil extract, humic acid, dextrans, urea, glutamic acid, hypoxanthine, gibberellic acid, indol acetic acid, kinetin, polyamines, lectins of Phaseolus and porcine blood platelets) [32], and live prey (bacteria, pico- and nanoplankton, and yeast) [33]. None of these trials with organic materials supported Dinophysis spp. growth enough to allow for successful isolation of the genera and the establishment of cultures, leading to the assumption that Dinophysis could not directly utilize organic compounds.

Recent studies with isolates, however, demonstrate that a variety of organic materials, and some inorganics, may benefit Dinophysis by indirectly or directly supporting growth and/or toxin production. Toxin production, but not growth, increased when a non-axenic monoculture of $D$. acuminata was supplemented with lysed ciliates and cell debris during a preliminary study [21], and D. acuminata growth in monocultures and predator-prey co-incubations was enhanced with the addition of urea, glutamine, or waste water organic matter [24]. With respect to inorganic nutrients, three recent studies have confirmed that $D$. acuminata does not readily utilize nitrate to support growth $[24,34,35]$ or toxin production [34,35], but that the ciliate prey rapidly assimilates nitrate to promote its own division, thereby indirectly supporting D. acuminata [35]. Ammonium, interestingly, was shown to likely play a direct role in $D$. acuminata growth, bloom development, and toxin production, through uptake of this inorganic compound by the dinoflagellate $[24,34,36,37]$. What's improved in these later culturing studies, as compared to Nagai et al. [21], is that compounds of interest were added to Dinophysis with and without prey as a food source, examining therefore, growth and toxin production during mixotrophic and phototrophic growth.

By including prey in a treatment with possible nutrient sources, additional questions can be asked regarding the combined roles of ciliates and nutrients in dinoflagellate growth and toxin production. More specifically, a pairing of prey cells and prey exudate or lysate seems more environmentally relevant than testing in solidarity, as the two are likely found in conjunction within a system. Co-occurrence of cells and released internal components, for example, may occur throughout a bloom, 
due to such processes as sloppy feeding or cell division; however, the presence of these compounds likely increases in the surrounding waters near the termination of a ciliate bloom when cells may be experiencing aging and membrane permeability, parasitic lysis, or cell death. This progression has been demonstrated in the laboratory for endotoxins OA and DTX1 [21,38]. Additionally, ciliates should be considered in this relationship as laboratory studies [10,39-41] have indicated prey abundance as an important controller of Dinophysis growth and/or toxin production, and Dinophysis spp. have been found to bloom immediately after and co-occur with ciliate prey in the field [42], suggesting that factors controlling ciliate abundance and distribution are important to down-stream DSP events. Further research is now needed to further understand how inorganic and organic compounds interact with prey and a variety of Dinophysis spp. and isolates if predictive capabilities are to be developed and management strategies created.

Building on a previous study [21], mixotrophic D. acuminata was investigated for its ability to utilize organic material released from the ciliate, M. rubrum in the presence or absence of the ciliate as a food source, i.e., during mixotrophic vs. phototrophic growth, respectively. We supplemented a D. acuminata culture, comprising of $\mathrm{f} / 6-\mathrm{Si}$ medium [43], with ciliate lysate (derived from probe-sonification of ciliate culture), ciliate lysate and live ciliates, or live ciliates alone at two initial cell concentrations (Table 1). To determine if any measured effect on D. acuminata growth or toxin production was unique to the ciliate lysate, we also amended $D$. acuminata culture with cryptophyte lysate or live cryptophytes. All treatments were compared to a monoculture control of D. acuminata with no organic amendments, and cultures of D. acuminata were starved, in the light, for two weeks before the experiment to ensure that any responses measured in the dinoflagellate were due to the amendments, and not sustained growth or divisions using internal reserves. While the main objective of this study was to begin investigating, in the laboratory, if organic matter derived from a co-occurring bloom of ciliates could support Dinophysis growth and toxin production either directly or indirectly, the information may also have implications for future D. acuminata isolation attempts. If lysate, for example, promotes $D$. acuminata growth, then this may be a mechanism to increase the likelihood of isolation success.

Table 1. Prey, lysate, or a mixture of the two were provided as nourishment during culturing experiments with a Dinophysis acuminata isolate after dinoflagellates were starved for two weeks in the light. Treatments included the addition of live prey and/or probe-sonified lysate of the ciliate, Mesodinium rubrum, delivered at two initial cell concentrations or equivalents (eq.). The cryptophyte, Teleaulax amphioxeia, was also provided in two treatments: live prey or lysate. Treatments were compared to a Dinophysis monoculture control where no prey or lysate were added, and instead an equivalent volume was replaced with additional fresh $\mathrm{f} / 6$-Si medium. Mean ( \pm standard error) measurements of Dinophysis growth rate and biomass are provided.

\begin{tabular}{|c|c|c|c|c|c|c|}
\hline \multirow[b]{2}{*}{ Treatment ID } & \multirow[b]{2}{*}{$\begin{array}{l}\text { Prey/Lysate } \\
\text { Species }\end{array}$} & \multirow[b]{2}{*}{$\begin{array}{c}\text { Prey Initial } \\
\text { Conc. } \\
\text { (Cells/mL) }\end{array}$} & \multirow[b]{2}{*}{$\begin{array}{l}\text { Lysate Initial Conc. } \\
\text { (Cell eq./mL) }\end{array}$} & \multicolumn{3}{|c|}{ Dinophysis Growth ${ }^{1}$} \\
\hline & & & & $\begin{array}{c}\text { Exponential } \\
\text { Growth } \\
\text { Rate (/d) }\end{array}$ & $\begin{array}{c}\text { Period of } \\
\text { Exponential } \\
\text { Growth (d) }\end{array}$ & $\begin{array}{c}\text { Max } \\
\text { Biomass } \\
\text { (cells/mL) }\end{array}$ \\
\hline Prey $_{\text {ciliate }} 3000$ & M. rubrum & 3000 & - & $0.21( \pm 0.003)$ & 12 & $2508( \pm 162)$ \\
\hline Prey $_{\text {ciliate }} 1500$ & M. rubrum & 1500 & - & $0.16( \pm 0.007)$ & 15 & $2252( \pm 110)$ \\
\hline Prey + Lysate ciliate $^{3000}$ & M. rubrum & 1500 & 1500 & $0.25( \pm 0.002)$ & 12 & $3902( \pm 234)$ \\
\hline Lysate $_{\text {ciliate }} 3000$ & M. rubrum & - & 3000 & $0.12( \pm 0.004)$ & 3 & $302( \pm 8)$ \\
\hline Prey & T. amphioxeia & 15,000 & - & - & - & $170( \pm 8)$ \\
\hline Lysate $_{\text {crypto }}$ & T. amphioxeia & - & 15,000 & - & - & $193( \pm 7)$ \\
\hline Control & none & - & - & - & - & $187( \pm 5)$ \\
\hline
\end{tabular}

${ }^{1}$ Dinophysis initial cell concentration was equal for all 6 treatments and the control, 150 cells $/ \mathrm{mL}$. The symbol "_" indicates zero. 


\section{Results}

\subsection{Lysate Size Characterization}

Particles $(n=185)$ in the ciliate lysate were photographed and measured under a light microscope at $100 \times$. The mean size of lysate particles was $3.41 \pm 0.13 \mu \mathrm{m}$ (mean \pm standard error) in diameter and $9.17 \pm 0.73 \mu \mathrm{m}^{2}$ in area. Attempts were also made to characterize particles in the cryptophyte lysate; however, particles were not large enough to quantify using supplied magnification and software.

\subsection{Growth of Dinoflagellate, Ciliate, and Cryptophyte}

Dinoflagellates grew exponentially in the four treatments that were fed live ciliates (1500 or 3000 cells $/ \mathrm{mL}$ ), a 1:1 mixture of living ciliates and lysate (equivalent to 3000 cells $/ \mathrm{mL}$ ), and only ciliate lysate (equivalent to 3000 cells $/ \mathrm{mL}$ ). More specifically, growth rates were $0.16 \pm 0.007,0.21 \pm 0.003$, $0.25 \pm 0.002$, and $0.12 \pm 0.004 / d$ for treatments Prey ciliate $^{1500}$, Prey $_{\text {ciliate }}{ }^{3000}$, Prey + Lysate $_{\text {ciliate }}{ }^{3000}$, and Lysate $_{\text {ciliate }}{ }^{3000}$, respectively (Table 1, Figure 1). When compared across treatments providing the same concentration of ciliates, 3000 cell eq. $/ \mathrm{mL}$, Dinophysis grew faster when provided prey or a combination of prey and lysate (treatments Prey ciliate $^{3000}$ and Prey + Lysate $_{\text {ciliate }}{ }^{3000}$ ), than when provided only lysate $\left(\right.$ Lysate $\left._{\text {ciliate }}{ }^{3000}\right)(t$-test, $p<0.05)$. Similarly, when provided both ciliate prey and lysate (Prey + Lysate $\left._{\text {ciliate }}{ }^{3000}\right)$, Dinophysis reached a higher maximum, final biomass $(3900 \mathrm{cell} / \mathrm{mL})$ at plateau phase than when it was provided with only living ciliates (Prey ciliate $^{3000}$ ), 2500 cells $/ \mathrm{mL}$, or only lysate (Lysate ciliate $^{3000}$ ), 302 cells /mL (Table 1, Figure 1). The average maximum biomass of Dinophysis in the Lysate ciliate $^{3000}$ treatment was significantly greater than the maximum biomass measured in the monoculture control, showing that growth was supported for three days on materials liberated from the ciliate lysate (after two weeks of starvation in the light). When comparing between treatments providing live ciliates, Dinophysis grew significantly faster during exponential growth in the 3000 cells $/ \mathrm{mL}$ treatment $\left(\right.$ Prey $_{\text {ciliate }}{ }^{3000}$ ) than in the 1500 cells $/ \mathrm{mL}$ treatment $\left(\right.$ Prey $\left._{\text {ciliate }}{ }^{1500}\right)$; however, Dinophysis in the latter treatment grew steadily for a longer period, resulting in no detectable difference in maximum biomass between treatments (Table 1). The dinoflagellates in treatments that were provided with either living cryptophytes (Prey crypto $_{\text {), }}$ cryptophyte lysate (Lysate crypto $_{\text {), or no }}$ additions (Control, growth rate $=0.01 \pm 0.007 / \mathrm{d}$ ) did not show evidence of exponential growth over the experimental period (Table 1, Figure 1).

The cell concentrations of ciliates and cryptophytes were also monitored in the co-incubations. The cell concentration of the ciliate quickly decreased over time as Dinophysis fed during exponential growth. More specifically, ciliates were completely consumed by days 15-18 in the two treatments to which they were added without lysate: Prey ciliate $^{1500}$ and Prey ciliate $^{3000}$ (Figure 1). The prey in the Prey + Lysate $_{\text {ciliate }}{ }^{3000}$ treatment were depleted from the co-incubation by day 12 , however, transitioning Dinophysis into a prey-limited phase earlier than the other two treatments with live ciliates. The cryptophytes that were co-incubated with Dinophysis (Prey crypto) grew exponentially for 12 days, reaching a maximum concentration of 600,000 cells $/ \mathrm{mL}$ during the experimental period (data not shown). 


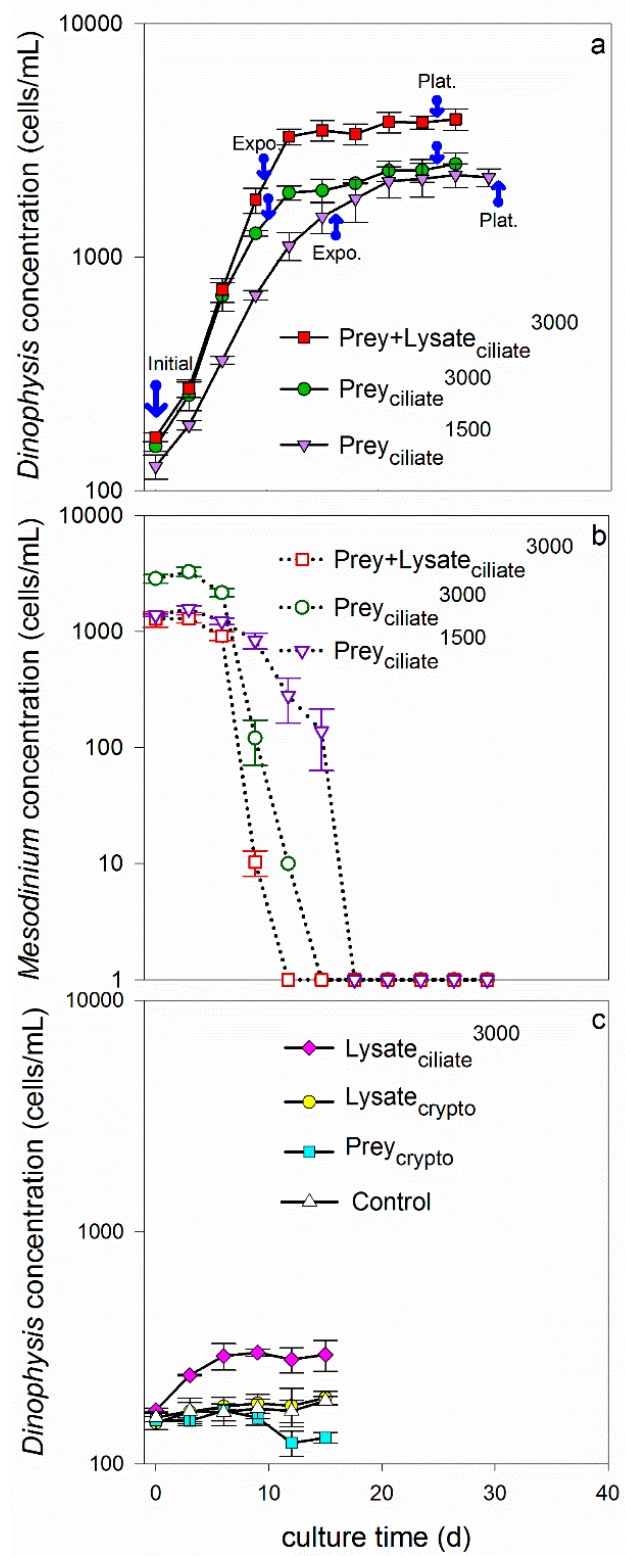

Figure 1. Growth response of Dinophysis acuminata (a,c) and ciliates, M. rubrum (b), in different treatments after being starved, in the light, for two weeks before the experiment to ensure the prey were fully consumed from the medium and that any responses measured in Dinophysis were due to the amendments and not sustained growth or divisions using internal reserves. Treatments include Prey $_{\text {ciliate }}{ }^{3000}$ : with ciliates at 3000 cells $/ \mathrm{mL}$; Prey + Lysate $_{\text {ciliate }}{ }^{3000}$ : with ciliates at $1500 \mathrm{cells} / \mathrm{mL}$ + ciliate lysate equivalent to 1500 cells $/ \mathrm{mL}$; Prey ciliate $^{1500}$ : with ciliates at 1500 cells/mL (a,b); Lysate $_{\text {ciliate }} 3000$ : with ciliate lysate equivalent to 3000 cells $/ \mathrm{mL}$; Lysate ${ }_{\text {crypto }}$ : with cryptophyte lysate

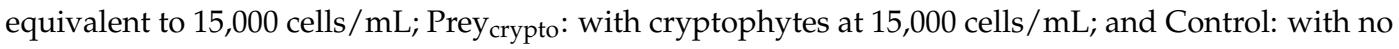
prey or lysate addition (c). Initial concentration of D. acuminata was 150 cells $/ \mathrm{mL}$ for all treatments. Mean values and standard deviations are plotted $(n=3)$. Blue arrows in $(\mathbf{a})$ indicate when samples were initially harvested for toxin analysis, and then during exponential (Expo.) and plateau (Plat.) growth phases.

\subsection{Toxin Quota, Concentration, and Production}

Cells and media of Dinophysis were harvested separately and analyzed for toxin during two growth phases, exponential and plateau, for three treatments: Prey ciliate $^{1500}$, Prey ciliate $^{3000}$, and Prey + Lysate $_{\text {ciliate }}{ }^{3000}$. Initial toxin samples were also collected and analyzed from the inoculum 
Dinophysis cultures for comparison. Toxin data are not reported for the other four treatments, because growth rates and final biomass were significantly lower when Dinophysis was grown with only ciliate lysate, grown with cryptophytes that were living or lysed, or grown as a monoculture control. More specifically, Dinophysis in these latter treatments (1) produced insufficient biomass to reach toxin detection limits, and/or (2) did not progress through typical growth phases, i.e., lag, exponential, and plateau, during the experimental period, making the toxin data incomparable to the high-growth treatments.

We calculated the potential loss of D. acuminata during the harvesting process for toxin samples, i.e., sieving. Only $1 \%$ of the harvested cells were potentially lost during harvesting; possible mechanisms include being trapped in/on the sieve, loss of small cells, and/or artificial cell lysis during processing. This error was found to be minimal and constant over growth phases, and therefore, considered irrelevant to this study.

Toxin quotas (intracellular toxin) and concentrations (extracellular toxins) measured during exponential and plateau phases were compared to the initial toxin levels in the maintenance Dinophysis culture that was used for inoculation (taken in late plateau phase) to demonstrate increases in toxin relative to initial conditions. As a general trend, intracellular levels of OA, DTX1, and PTX2 remained minimal, i.e., similar to initial levels, during exponential growth, but increased during plateau phase (Figure 2a-c). Exceptions were observed, however, whereby Dinophysis that was provided ciliate prey at an initial concentration of 3000 cells $/ \mathrm{mL}$ (Prey ciliate $^{3000}$ ) did not increase their OA toxin quota, relative to initial conditions, over the entire experimental period. Additionally, Dinophysis fed the lower initial concentration of ciliate $\left(\right.$ Prey $_{\text {ciliate }}{ }^{1500}$ ) did not increase their internal quotas of DTX1 or PTX2 above initial conditions over the entire experimental period. Maximum average toxin quotas were reached during plateau phase for OA, $0.11 \pm 0.01 \mathrm{pg} \mathrm{OA} /$ cell (Prey + Lysate ciliate $^{3000}$ ); DTX1, $0.20 \pm 0.02 \mathrm{pg} /$ cell (Prey + Lysate ciliate $^{3000}$ ); and PTX2, $28.38 \pm 5.02 \mathrm{pg} /$ cell $\left(\right.$ Prey $_{\text {ciliate }}{ }^{3000}$ ).

As seen with intracellular toxin quotas, extracellular toxin concentrations of OA, DTX1, and PTX2 in the culture medium of the three treatments remained low, relative to initial toxin concentrations, through exponential growth, but significantly increased by plateau phase (Figure 2d-f). Maximum, average extracellular toxin concentrations were reached during plateau growth phase for OA, $1.37 \pm 0.01 \mathrm{ng} / \mathrm{mL}$ (Prey + Lysate $_{\text {ciliate }}{ }^{3000}$ ) DTX1, $1.27 \pm 0.10 \mathrm{ng} / \mathrm{mL}$ (Prey + Lysate $_{\text {ciliate }}{ }^{3000}$ ); and PTX2, $22.37 \pm 0.54 \mathrm{ng} / \mathrm{mL}$ (Prey ciliate $^{1500}$ ). Once the intracellular quotas were converted to intracellular toxin concentrations per milliliter of culture and combined with extracellular toxin concentrations to yield total toxin concentrations (Figure 2g-i), it became apparent that total toxin concentration showed the same overall pattern across treatments; total toxins increased over the aging of the culture and reach maximum levels by plateau phase. DSP toxins, OA and DTX1, were more associated with the extracellular fraction, $<15 \mu \mathrm{m}$, while PTX2 was associated with the cells and particulates, $\geq 15 \mu \mathrm{m}$.

Total toxin concentrations, toxin quotas, and extracellular concentrations were also compared across treatments during plateau phase to look for any effect from the different organic amendments (Figure 2). Overall, the total toxin concentrations of OA and DTX1 were significantly greater in the Prey + Lysate ciliate $^{3000}$ treatment, as compared to the treatments with only live ciliates added $\left(\right.$ Prey $_{\text {ciliate }}{ }^{1500}$, Prey ciliate $^{3000}$ ). When evaluating intra and extracellular toxins separately, the same trend remained: the mean OA toxin quota and DTX1 extracellular concentration were significantly greater than treatments with live prey. Okadaic acid extracellular concentrations (Figure 2d) and DTX1 intracellular toxin quotas (Figure $2 b$ ), however, were indistinguishable between the two treatments with lysate (Prey + Lysate $_{\text {ciliate }}{ }^{3000}$ ) and the higher prey abundance $\left(\right.$ Prey $_{\text {ciliate }}{ }^{3000}$ ). In all cases, Prey + Lysate $_{\text {ciliate }}{ }^{3000}$ and the higher prey abundance Prey ciliate $^{3000}$ contained more OA or DTX1 in the intra or extra cellular fractions than the treatment with the lowest prey abundance (Prey $\left.{ }_{\text {ciliate }}{ }^{1500}\right)$. Pectenotoxin-2 levels did not follow a distinguishable trend across treatments or toxin measurements, but values were more than a magnitude greater than OA and DTX1 combined. 

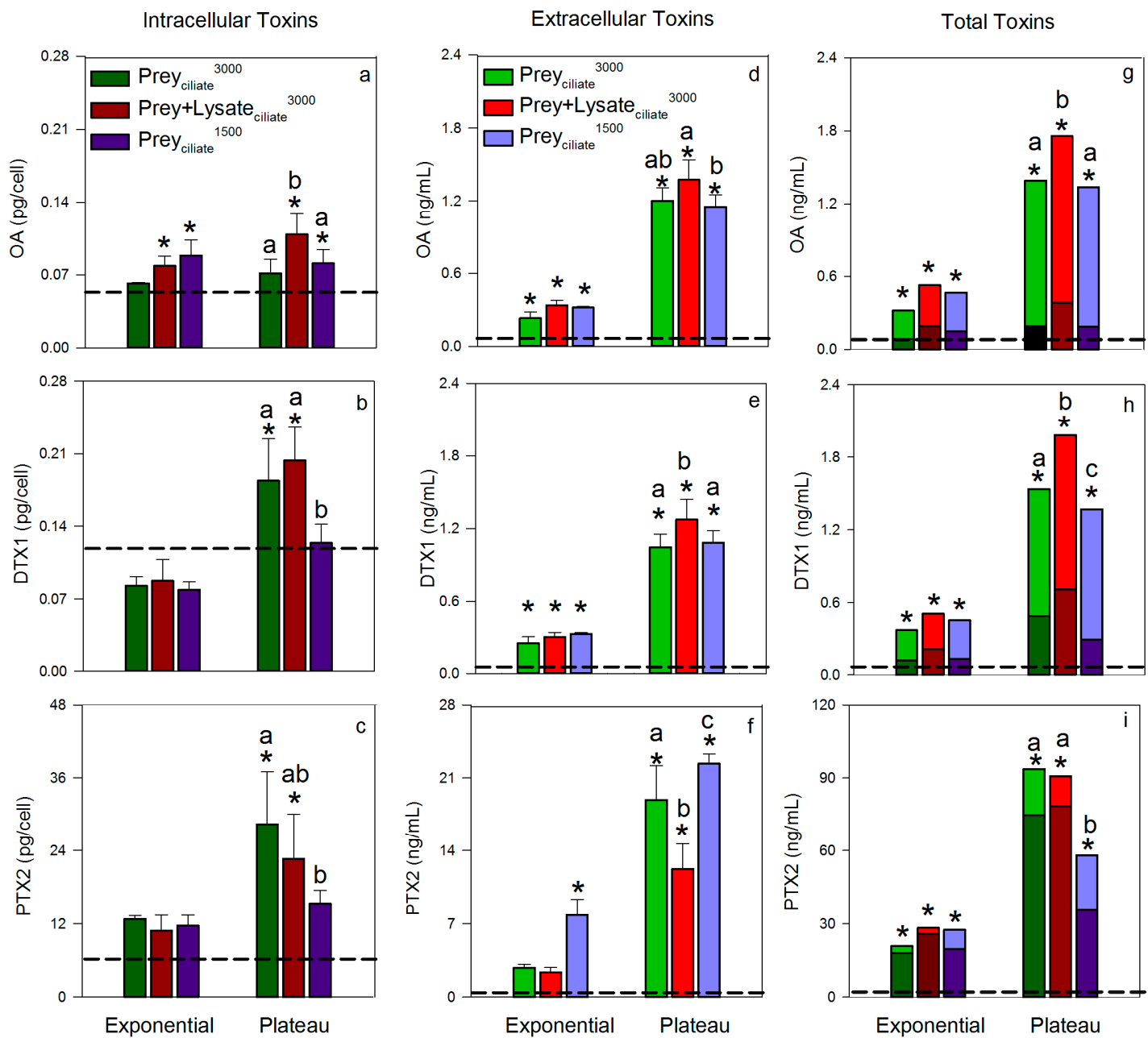

Figure 2. Toxin levels in Dinophysis acuminata cells and medium over two growth phases: exponential and plateau for three treatments. (a-c, Mean $\pm \mathrm{SD}, n=3)$ intracellular toxin quotas, $(\mathbf{d}-\mathbf{f}$, Mean $\pm \mathrm{SD}$, $n=3$ ) extracellular toxin concentrations in the cultures, and ( $\mathbf{g}-\mathbf{i})$ total toxin concentration in D. acuminata cultures with ciliate prey and/or lysate (Mean, $n=3$ ). Intracellular toxins are indicated with darker color bars, while extracellular toxins are represented using the lighter color bars. Toxins quantified include okadaic acid (OA), dinophysistoxin-1 (DTX1), and pectenotoxin-2 (PTX2). Dashed horizontal line in each panel indicates the mean initial toxin level at the start of the experimental period. Asterisks ${ }^{* \prime}$ indicate that a treatment was significantly greater at that growth phase as compared to the initial toxin level, and letters that are uncommon show significant difference $(p<0.05)$ in toxin levels between treatments during plateau phase, within that respective panel only.

The rate of intracellular toxin production (OA, DTX, or PTX2) by Dinophysis was greater during exponential growth phase than as cells transitioned into plateau phase (Table 2). Toxin production rates of OA, DTX1, and PTX2 were significantly faster $(p<0.05)$ when Dinophysis was provided with a mixture of prey and lysate (Prey + Lysate ciliate $^{3000}$ ) than when provided the same concentration of prey, but no lysate $\left(\right.$ Prey $\left._{\text {ciliate }}{ }^{1500}\right)$. Toxin production in the mixed treatment and higher prey treatment $\left(\right.$ Prey $\left._{\text {ciliate }}{ }^{1500}\right)$ were more comparable. Toxin production occurred during the transition from exponential to plateau phase as well; however, rates of OA, DTX1, and PTX2 production were reduced (Table 2). 
Table 2. Mean ( \pm standard error) calculations of Dinophysis toxin production rate over two growth phases, exponential (expo.) and plateau (plat.). The duration of days used to represent each growth phase, and therefore calculate net toxin production rate $\left(\mathrm{R}_{\mathrm{tox}}\right)$, are included for reference. Statistical differences are indicated by uncommon lowercase letters (Two-Way Repeated Measures ANOVA with alpha set to $0.05, n=3)$.

\begin{tabular}{|c|c|c|c|c|c|c|c|c|}
\hline \multirow{3}{*}{ Treatment ID } & \multicolumn{2}{|c|}{$\begin{array}{l}\text { Duration of Each } \\
\text { Growth Phase (d) }\end{array}$} & \multicolumn{6}{|c|}{ Dinophysis $\mathbf{R}_{\text {tox }}(\mathrm{fg} /$ cell/d) } \\
\hline & \multirow{2}{*}{ Expo. } & \multirow{2}{*}{ Plat. } & \multicolumn{3}{|c|}{ Initial to Exponential } & \multicolumn{3}{|c|}{ Exponential to Plateau } \\
\hline & & & OA & DTX1 & PTX2 & OA & DTX1 & PTX2 \\
\hline Prey $_{\text {ciliate }} 3000$ & 10 & 15 & $46( \pm 4)^{\mathrm{a}}$ & $56( \pm 4)^{\mathrm{a}}$ & $3747( \pm 177)^{a b}$ & $40( \pm 4)^{a}$ & $44( \pm 2)^{a}$ & $2837( \pm 241)^{a}$ \\
\hline Prey $_{\text {ciliate }} 1500$ & 16 & 16 & $39( \pm 1)^{a}$ & $37( \pm 1)^{b}$ & $2723( \pm 234)^{b}$ & $24( \pm 1)^{b}$ & $26( \pm 2)^{b}$ & $920( \pm 58)^{\mathrm{b}}$ \\
\hline Prey + Lysate ciliate $^{3000}$ & 10 & 15 & $65( \pm 3)^{b}$ & $63( \pm 5)^{a}$ & $4171( \pm 573)^{a}$ & $30( \pm 1)^{a b}$ & $37( \pm 4)^{a b}$ & $1662( \pm 372)^{b}$ \\
\hline
\end{tabular}

OA, okadaic acid. DTX1, dinophysistoxin-1. PTX2, pectenotoxin-2.

\section{Discussion}

Mixotrophic Dinophysis acuminata was investigated for its ability to utilize organic material released from the ciliate, Mesodinium rubrum, or the cryptophyte, Teleaulax amphioxeia. As such, an isolate of D. acuminata was grown in the presence of live cells, lysate, live cells and lysate, or no amendments except fresh culture medium. Overall, the addition of ciliate lysate, but not cryptophyte lysate, to co-incubations of predator and prey led to significantly higher Dinophysis growth rate, biomass, OA toxin quotas, DTX1 extracellular toxin concentrations, and DSP total toxins (Figures 1 and 2, and Tables 1 and 2). It is important to note, that the addition of ciliate lysate to co-incubations increased growth and toxigenicity above similar treatments where Dinophysis was provided with the same or more live ciliate prey (1500 and 3000 cells $/ \mathrm{mL}$, respectively) or the same amount of overall ciliate biomass as lysate $(3000$ cell eq $/ \mathrm{mL})$. Together these results demonstrate that the organic matter from the lysed ciliates provided the necessary nutrition to Dinophysis (directly or indirectly) to support growth (phototrophic or mixotrophic, respectively) and toxin production by the dinoflagellate.

\subsection{Ciliate Lysate in Support of Growth}

Early culturing experiments proposed that Dinophysis acuminata required both prey and light to grow in culture $[10,22,39-41]$; however, more recently, D. acuminata has been shown to undergo phototrophic growth, in the presence of ammonium and urea, and the absence of prey, but that growth occurs at a slower rate than during mixotrophy [34,36]. Similarly, in the present study, an isolate of $D$. acuminata from Eel Pond, USA, grew for 3 days and reached significantly higher biomass when provided only ciliate lysate as an amendment beyond medium (Lysate ciliate $^{3000}$, Figure 1) as compared to a monoculture control that showed no growth or change in biomass over the same period. These dinoflagellate cultures were starved for two weeks in the light prior to the experiment to ensure that internal reserves were depleted and that any responses measured in Dinophysis were due to the new amendments. While certain growth (photosynthetic + mixotrophic) occurred without prey in the ciliate lysate treatment (Lysate ${ }_{\text {iliate }}{ }^{3000}$ ), growth rates and final biomass significantly increased once prey were added to D. acuminata culture (Prey + Lysate $_{\text {ciliate }}{ }^{3000}$, Prey $_{\text {ciliate }}{ }^{1500}$, Prey $_{\text {ciliate }}{ }^{3000}$ ) (Table 1), supporting previous findings for faster growth rates during mixotrophic growth. It is unclear whether the dinoflagellate directly and/or indirectly benefitted from the organic materials liberated from the ciliates. Other studies have proposed an indirect link between dissolved nutrients and Dinophysis abundance, citing the ciliate's high affinity for dissolved inorganic and organic nutrients and a cascading increase in ciliate abundance and then Dinophysis abundance [34,35,44]. Ciliates, however, did not increase in abundance or extend their presence in the co-incubation with the addition of lysate (Figure 1b); this is contrary to what can be expected if the ciliate was the link between the liberated organic materials and increased Dinophysis abundance. This result, instead, lends support 
for an alternative conclusion: D. acuminata directly used the liberated materials to enhance total (photosynthetic + mixotrophic) growth on top of mixotrophic growth.

The growth-promoting effect of ciliate lysate also surpassed the effects of doubling ciliate abundance and exceeding prey saturation levels. More specifically, doubling the concentration of live ciliates inoculated into co-incubations from 1500 to 3000 cells $/ \mathrm{mL}$ (Prey ciliate ${ }^{1500}$, Prey ciliate $^{3000 \text {, }}$ respectively), significantly increased Dinophysis growth rate (Figure 1, Table 1). This increase in rate and biomass achieved with more prey, however, was still below that achieved by D. acuminata when grown in the presence of lysate and less prey (Prey + Lysate ciliate $^{3000}$ ). Differences in growth rate between the low and high prey treatments were expected given that the initial prey concentrations, 1500 and 3000 cells/mL respectively, were below and above the published prey saturation threshold: $\sim 2000$ cells $/ \mathrm{mL}[39,45]$. The design of these treatment levels was intentional in that it allowed for the examination of whether a sub-saturation level of live prey, as seen in treatments Prey + Lysate ciliate $^{3000}$ and Prey ciliate $^{1500}$, would lead to similar maximum Dinophysis growth rates and biomass, or if supplementing that sub-saturation level of prey with lysate would allow D. acuminata to perform at the level of super-saturation, i.e., equivalent to the high prey treatment, Prey $_{\text {ciliate }} 3000$. As the latter outcome was observed, i.e., D. acuminata grew fastest in the lysate and prey treatment $\left(\right.$ Prey + Lysate $_{\text {ciliate }}{ }^{3000}$ ), one can conclude that either (1) the ciliate (or associated bacteria) utilized the liberated materials promoting $D$. acuminata growth by making itself more enriched or abundant, or (2) with the addition of ciliate lysate, total (photosynthetic + mixotrophic) growth was enhanced in D. acuminata (i.e., direct uptake of liberated materials by dinoflagellate).

Alternatively, the bacteria associated with the ciliate culture inoculum may be indirectly responsible for the measured increase in D. acuminata growth in the mixed treatment (Prey + Lysate $_{\text {ciliate }}{ }^{3000}$ ). The three cultures of cryptophyte, ciliate, and dinoflagellate used in this study were non-axenic, and so likely contained heterotrophic bacteria at the time of co-incubation. Bacteria, in general, are well known for their contributions to phytoplankton growth [46-48], and may have remineralized the organic material (dissolved or particulate) into nutrient chemical forms that $D$. acuminata can directly utilize to support cell division, such as ammonium or urea $[34,49]$. Growth factors, such as essential vitamins and metals, may also be liberated through remineralization of dissolved organic substrates. Therefore, interactions between Dinophysis-ciliate-bacteria still need to be evaluated systematically if the link between the dinoflagellate, ciliate, and/or organic compounds or materials is to be realized.

As ciliate lysate was shown to enhance $D$. acuminata growth in the presence of ciliate inoculum (i.e., live ciliates and associated bacteria), then ciliate lysate addition may be a mechanism to increase the likelihood of success during D. acuminata isolation. While early attempts to isolate and establish Dinophysis cultures with organic matter failed [32,33], more recent studies with field populations and established isolates suggest Dinophysis experiences direct or indirect benefits from organic compounds $[21,24,34,36]$ and this study. Given how critical the multi-stage feeding scheme [10] is to the successful isolation of Dinophysis spp., we do not recommend replacing prey with ciliate lysate, but instead suggest that in addition to typical Dinophysis isolation methods, researchers consider adding equal parts of live ciliates and ciliate lysate to a subset of single-cells in a well plate. Note that the growth-promoting effect of ciliate lysate has only been demonstrated for $D$. acuminata and so it is not known if these results extrapolate to others in the genus. Additionally, ciliates used in this study were maintained by performing a 1:2 dilution with fresh medium (see Materials and Methods), meaning that ciliates were likely conditioned to utilize additional nutrient forms than those that are strictly provided in $\mathrm{f} / 6-\mathrm{Si}$ medium. It is, therefore, unknown if the growth-promoting effect of ciliate lysate, in the present study, was dependent upon the pre-conditioning of ciliates, and therefore D. acuminata, to utilize multiple chemical forms. 


\subsection{Ciliate Lysate in Support of Toxin Production}

The addition of a mixture of ciliate lysate and live ciliates to D. acuminata cultures significantly increased total toxin concentrations (intracellular + extracellular) of OA and DTX1 relative to both initial levels and the other treatments that provided only ciliates (Figure $2 \mathrm{~g}-\mathrm{h}$ ). Pectenotoxin-2 did not show a consistent trend across treatments and toxin fractions, but did significantly increase in the lysate and prey treatment from initial levels (Figure $2 \mathrm{c}, \mathrm{f}, \mathrm{i})$. These novel findings built upon a previous study by Nagai et al., [21], whereby the authors showed that the addition of lysate alone increased total toxin levels in a monoculture of D. acuminata. While the current study cannot ask the same question, i.e., the lysate-only treatment did not produce enough biomass for toxin testing, it is interesting that both studies reported a toxin-promoting effect of lysate. The consistency in results between studies, two geographical isolates, and different prey lines, lends support to this result's validity. Additionally, the earlier depletion of live ciliates from the Prey + Lysate ciliate $^{3000}$ treatment (Figure 1b) may have contributed to the enhanced toxin quotas in D. acuminata as toxin content has been shown to increase in cultures during the prey-limited phase (52).

Okadaic acid and DTX1 released into the surrounding environment, whether actively or passively, by $D$. acuminata may have detrimental effects on competitors and prey. These toxins have been shown to limit the growth of several microalgae $[5,6]$ and have been proposed to aid in the capture and immobilization of ciliate prey $[31,40,50,51]$. Ciliates, M. rubrum, exhibited abnormal behavior when exposed to high densities of $D$. fortii, such as forming clumps or rotating at the same place, followed by death [51]. Other mechanisms of capture have also been investigated, such as mucus traps [30] and chemical or physical sensing [52,53], in which OA has either been found unimportant to the mechanism or not evaluated as a contributor. The present study suggests a positive feedback may occur, whereby the addition of prey lysate enhances the production and exudation of DSP toxins. The addition of ciliate lysate to co-incubations (Prey + Lysate ciliate $^{3000}$ ) resulted in a significant increase in OA and DTX1 levels to 0.38 and $0.71 \mathrm{ng} / \mathrm{mL}$ intracellularly, and 1.37 and $1.27 \mathrm{ng} / \mathrm{mL}$ extracellularly by plateau phase, respectively (Figure 2g-h). Mechanisms underlying this feedback, e.g., chemical detection of prey [52], should be further explored as these data suggest that the presence of cells and/or their exudate will enhance extracellular DSP toxin levels.

\section{Conclusions}

To summarize, an isolate of $D$. acuminata benefitted from the addition of organic matter that was released from M. rubrum by probe-sonification. Growth and DSP toxin metrics elevated when the lysate was administered with live prey, suggesting that either total (photosynthetic + mixotrophic) growth of $D$. acuminata was enhanced with the addition of the liberated organic compounds and/or the ciliate (or associated bacteria) was directly utilizing the liberated materials and indirectly providing the benefit to $D$. acuminata through remineralization to bioavailable forms or increasing ciliate enrichment and/or abundance. When provided with ciliate lysate only, however, growth of $D$. acuminata was also observed, lending some support to the conclusion that the dinoflagellate does have some capacity to directly utilize the liberated compounds itself and promote certain growth and toxin production.

Extrapolating to the field, these culturing studies suggest that the co-occurrence of a ciliate-dinoflagellate bloom may exacerbate $D$. acuminata abundance and toxigenicity due to exudate or lysing. The lysate from the cryptophyte, however, did not support Dinophysis growth, suggesting this growth-promoting effect may be unique to ciliates. Further studies should be conducted to better understand the interactions between organic compounds and Dinophysis-ciliate-bacteria relationships and characterize the nutritional composition of ciliate lysate to identify the beneficial components as those might be important drivers of D. acuminata abundance and DSP events in the field. 


\section{Materials and Methods}

\subsection{Culture Maintenance}

A uni-algal culture of Dinophysis acuminata (DAEP01) was previously isolated from Eel Pond, Woods Hole, MA, in September of 2006 [54]. The ciliate Mesodinium rubrum (GenBank accession NO. AB364286) and cryptophyte Teleaulax amphioxeia (GenBank accession NO. AB364287) were isolated from Inokushi Bay in Oita Prefecture, Japan, in February of 2007 as described in [27]. All cultures were maintained at a salinity of 30 in $\mathrm{f} / 6$-Si medium, which was prepared with $1 / 3$ nitrate, $1 / 3$ phosphate, $1 / 3$ metals, and 1/3 vitamins of $\mathrm{f} / 2$-Si medium. The three-stage culture system [10] was utilized; the cryptophyte was fed to the ciliate prior to being fed to the dinoflagellate. In detail, every 7 days, $20 \mathrm{~mL}$ of M. rubrum culture medium was added to $20 \mathrm{~mL}$ of fresh $\mathrm{f} / 6-\mathrm{Si}$ medium with $0.5 \mathrm{~mL}$ T. amphioxeia cultures, providing roughly a 1:2 dilution of ciliate culture. After the cryptophyte cells were consumed, the ciliates were then fed to Dinophysis cells at a prey: predator ratio of 3:1. Cultures were maintained at $15{ }^{\circ} \mathrm{C}$ with dim light (ca. $20 \mu \mathrm{mol}$ photons $\mathrm{m}^{-2} \mathrm{~s}^{-1}$ ) on a $14 \mathrm{~h}$ light: $10 \mathrm{~h}$ dark photo cycle.

\subsection{Lysate Preparation and Size Characterization}

Mesodinium rubrum and T. amphioxeia cultures in early plateau phase (11 and 6 days old, respectively) were pretreated by probe sonication to prepare fresh ciliate and cryptophyte lysate for the experiment (Table 1). More specifically, $100 \mathrm{~mL}$ of the M. rubrum culture $\left(4 \times 10^{3} \mathrm{cells} / \mathrm{mL}\right)$ or $50 \mathrm{~mL}$ of the T. amphioxeia culture $\left(2 \times 10^{5}\right.$ cells $\left./ \mathrm{mL}\right)$ were probe sonified (Scientz JY92-IIN, Ningbo, China) using a repeated pulse cycle ( $3 \mathrm{~s}$ sonify $/ 3 \mathrm{~s}$ pause $=90 \mathrm{~s}$ of active sonication, power $=400 \mathrm{~W}$ ) over three minutes to lyse all cells. The duration and amplitude were determined by a preliminary experiment in which time of active sonification was increased from $60 \mathrm{~s}$ to $120 \mathrm{~s}$ over $200 \mathrm{~W}$ to $400 \mathrm{~W}$ (data not shown). No intact ciliate or cryptophyte cells were observed under a light microscope at $400 \mathrm{~W}$ after $60 \mathrm{~s}$ ultrasonic treatment.

Triplicate subsamples of experimental cell lysate were immediately scanned under light microscope using a Sedgewick-Rafter counting chamber to ensure the absence of living or whole cells. Particles of the ciliate lysate were photographed and measured using an Olympus CKX53 inverted microscope (Olympus, Shinjuku, Tokyo) with Infinity Analyze imaging software (Lumenera Corporation, Ottawa, Canada). All particles were evaluated as spheres, and therefore, were fit to a circle and diameter and area measurements collected.

\subsection{Experimental Design}

Triplicate maintenance cultures of Dinophysis acuminata and Mesodinium rubrum were starved, in the light, for two weeks before the experiment to ensure the prey were fully consumed from the medium and that any responses measured in Dinophysis were due to the amendments and not sustained growth or divisions using internal reserves. To begin the experiment, triplicate 1-L flasks were inoculated with Dinophysis monoculture at an initial concentration of 150 cell/mL for all seven treatments (Table 1). Live ciliate prey were then provided to Dinophysis at two initial concentrations, 1500 and 3000 cells /mL: the Prey ciliate $^{1500}$ and Prey ${ }_{\text {ciliate }}{ }^{3000}$ treatments, respectively. To determine if prey was equally supportive of growth and toxin production when provided as organic matter, half of the ciliates were lysed and then fed to Dinophysis as a mixture of live prey and lysate, equivalent to 3000 cells / mL: the Prey + Lysate $_{\text {ciliate }}{ }^{3000}$ treatment. Additionally, ciliate lysate equivalent to 3000 cells / mL was offered alone to determine if organic "dead" particles could support Dinophysis growth and toxin production: the Lysate $_{\text {ciliate }} 3000$ treatment. Prey to predator ratios for all the 1500 cells/mL and 3000 cells/mL ciliate treatments were 10:1 and 20:1, respectively.

Two additional treatments were included to determine if similar growth and toxin production could be achieved by Dinophysis through exposure to lysed cryptophytes, Lysate crypto $^{15000}$, with an equivalent live cryptophyte treatment run in parallel: Prey ${ }_{\text {crypto }}{ }^{15000}$ (Table 1). All treatments 
were compared to a monoculture Dinophysis control in which no prey or lysate was provided, and the triplicate flasks were instead supplemented with fresh $\mathrm{f} / 6$-Si medium to reach a similar final volume of $500 \mathrm{~mL}$.

Samples, $1.2 \mathrm{~mL}$, were taken every three days from each flask, fixed with $3 \%(v / v)$ formalin solution, and the dinoflagellates, ciliates, and cryptophytes were enumerated microscopically using a Sedgewick-Rafter counting chamber at $100 \times$ magnification.

\subsection{Toxin Analysis}

Culture was harvested and separated into medium and cells of Dinophysis once experimental cultures reached two growth phases, exponential and plateau. Initial toxin samples were also collected and analyzed from the Dinophysis inoculum cultures. Cells were separated from medium using a 15- $\mu \mathrm{m}$ Nitex sieve affixed to polyvinyl chloride (PVC) pipe and back-washed into a pre-weighed 15-mL centrifuge tube $\left(w_{1}\right)$ using fresh media; the sieved medium was collected into a beaker. As such, intracellular $(\geq 15 \mu \mathrm{m})$ and extracellular $(<15 \mu \mathrm{m})$ fractions of each sample were collected, extracted, and analyzed separately. In order to determine the total number of harvested cells for extraction, $200 \mu \mathrm{L}$ subsamples were pipetted from the intracellular toxin samples into a 2-mL micro-centrifuge tube containing $1.0 \mathrm{~mL}$ filtered seawater and $37 \mu \mathrm{L}$ formalin solution $(3 \% v / v)$. The fixed and diluted subsamples were enumerated microscopically to calculate cell concentration using a Sedgewich-Rafter counting chamber at $100 \times$ magnification. The $15-\mathrm{mL}$ tube was then reweighed $\left(w_{2}\right)$ to calculate the volume of harvested Dinophysis cells (v) using the formula:

$$
v=\frac{w_{2}-w_{1}}{\rho_{\text {seawater }}}
$$

where $\rho_{\text {seawater }}$ was set at $1.03 \mathrm{~g} / \mathrm{mL}$ given the salinity of the culture medium was 30 . The volume harvested $(v)$ was then multiplied by the cell concentration to estimate the total number of cells in the tube. Tubes were then frozen at $-80^{\circ} \mathrm{C}$ for over $24 \mathrm{~h}$ before toxin extraction.

Methods of solid phase extraction (SPE) were used as described in [38] to clean up samples prior to analysis. SPE cartridges (Oasis HLB $60 \mathrm{mg}$; Waters, Milford, MA, USA) were conditioned with $6 \mathrm{~mL}$ of methanol and rinsed with $6 \mathrm{~mL}$ of Milli-Q water in preparation for cell or media. Culture media (extracellular fraction, $<15 \mu \mathrm{m}$ ) was loaded onto the column immediately after separation from cells with no additional processing. Cell samples (intracellular fraction, $\geq 15 \mu \mathrm{m}$ ), however, underwent a freeze/thaw cycle and bath sonification (KQ-3200E, ultrasonic power $=150$ watt, frequency $=40 \mathrm{KHz}$, Kunshan Ultrasonic Instruments Co., Ltd., Kunshan, China) for $15 \mathrm{~min}$ at room temperature, to aid in cell lysis before being loaded onto the conditioned SPE cartridges. The cartridges were then washed with $3 \mathrm{~mL}$ of Milli-Q water and toxins were ultimately eluted with $1 \mathrm{~mL}$ of methanol into an autosampler vial. Eluates from the samples were heated at $40{ }^{\circ} \mathrm{C}$ in a heating block, dried under a stream of high-purity $\mathrm{N}_{2}$ (HP-S016SY, ), and re-suspended in $1 \mathrm{~mL}$ of methanol for toxin analysis to remove error associated with varying elution volumes. Eluates were frozen at $-20{ }^{\circ} \mathrm{C}$ until analysis.

The Dionex UltiMate 3000 liquid chromatrography system (Thermo Scientific ${ }^{\mathrm{TM}}$ Dionex $^{\mathrm{TM}}$, Waltham, MA, USA) coupled with an AB 4000 mass spectrometer (SCIEX, Framingham, MA, USA) with electrospray ionization (LC-MS/MS) was used for the analysis. Toxins, okadaic acid (OA) and dinophysistoxin-1 (DTX1), were analyzed in negative mode, and pectenotoxin-2 (PTX2) in positive mode. Chromatographic separation for OA and DTX1 was performed using a Waters XBridge ${ }^{\mathrm{TM}} \mathrm{C} 18$ column $(3.0 \times 150 \mathrm{~mm}, 3.5 \mu \mathrm{m}$ particle size $)$ at $40{ }^{\circ} \mathrm{C}$ in negative mode. The mobile phase used during negative mode consisted of phase $\mathrm{A}, 0.05 \mathrm{v} / \mathrm{v} \%$ ammonia hydroxide $(\mathrm{pH} 11)$ in water and phase $\mathrm{B}$, $0.05 \mathrm{v} / \mathrm{v} \%$ ammonia hydroxide in $90 \%$ acetonitrile, with a flow rate of $0.4 \mathrm{~mL} / \mathrm{min}$ and $10 \mu \mathrm{L}$ injection. A linear gradient elution from $10 \%$ to $90 \%$ B was run for $9 \mathrm{~min}$, held for $3 \mathrm{~min}$ at $90 \%$ B, decreased to $10 \% \mathrm{~B}$ in $2 \mathrm{~min}$ and held at $10 \% \mathrm{~B}$ for $4 \mathrm{~min}$ to equilibrate at initial conditions before the next run was started. In positive mode, Waters XBridge ${ }^{\mathrm{TM}} \mathrm{C} 18$ column $(2.1 \times 50 \mathrm{~mm}, 2.5 \mu \mathrm{m}$ particle size $)$ at $25{ }^{\circ} \mathrm{C}$ was performed for chromatographic separation of PTX2. The mobile phase consisted of phase C, 
water and phase $\mathrm{D}, 95 \%$ acetonitrile, both contain a constant concentration of buffer ( $2 \mathrm{mM}$ ammonium formate and $50 \mathrm{mM}$ formic acid). A linear gradient from $10 \%$ to $80 \%$ acetonitrile was run between 0 and $3 \mathrm{~min}$, held at $80 \%$ acetonitrile for $2 \mathrm{~min}$, decreased to $10 \%$ in $2 \mathrm{~min}$ and held another $2 \mathrm{~min}$. The flow rate during positive mode runs was $0.3 \mathrm{~mL} / \mathrm{min}$ and the injection volume was set to $10 \mu \mathrm{L}$.

The mass spectrometer was operated in multiple reaction monitoring (MRM) mode. Transitions of $\left[\mathrm{M}+\mathrm{NH}_{4}{ }^{+}\right]$ion: PTX2, $m / z 876.5>823.4,\left[\mathrm{M}-\mathrm{H}^{+}\right]$ions: $\mathrm{OA}, m / z 803.5>255.0$ and DTX1, $m / z 817.5>255.0$ were selected for quantitation. The operation conditions were as follows: ion spray voltage (ISV): $-4.5 \mathrm{kV}$, temperature (TEM): $600{ }^{\circ} \mathrm{C}$, nebulizer gas (NEB) 13 psi, curtain gas (CUR): 13 psi, collision gas (CAD): 5 psi in negative mode and ISV: $3 \mathrm{kV}$, TEM: $650{ }^{\circ} \mathrm{C}$, NEB: 14 psi, CUR: 16 psi, CAD: 5 psi in positive mode. Standards for OA, DTX1, and PTX2 were purchased from the National Research Council, Canada (NRC). Five-point standard curves were generated using NRC reference materials, with concentrations ranging from 1.25 to $20 \mathrm{ng} / \mathrm{mL}$ for OA and DTX1, and 6.25 to $100 \mathrm{ng} / \mathrm{mL}$ for PTX2.

\subsection{Calculations}

Dinophysis growth rate was calculated over the entire period of exponential growth phase (Table 1) using the following formula [55]:

$$
\mu=\frac{\ln \left(N_{2} / N_{1}\right)}{t_{2}-t_{1}}
$$

where $N_{1}$ and $N_{2}$ (cells $/ \mathrm{mL}$ ) are the cell concentrations at time 1 and time 2, respectively. Sampling times are represented by $t_{1}$ and $t_{2}$ with units of day, and $\mu$ is the growth rate calculated at the sampling interval with units of day ${ }^{-1}$.

Toxin data are presented as cellular toxin content or quota (toxin amount per cell), total toxin concentration (intracellular + extracellular, i.e., total toxin in a milliliter of culture), proportion of extracellular toxin (extracellular/ (intracellular + extracellular) $\times 100 \%$ ) and net toxin production rate $\mathrm{R}_{\text {tox }}$ (amount toxin/cell/d). The $\mathrm{R}_{\text {tox }}$ was calculated using the total toxin concentration (extracellular + intracellular) as described by the authors of [56].

$$
\begin{aligned}
R_{t o x} & =\frac{\left(T_{2}-T_{1}\right)}{(\bar{C})\left(t_{2}-t_{1}\right)} \\
\bar{C} & =\frac{C_{2}-C_{1}}{\ln \left(C_{2} / C_{1}\right)}
\end{aligned}
$$

In these equations, $T_{1}$ and $T_{2}$ are the total toxin concentrations (intracellular + extracellular, i.e., total toxin per milliliter of culture) at time 1 and time 2, respectively. Toxin production rates were calculated for two periods of time: from initial to exponential growth phase, and then from exponential into plateau phase (Table 2). The concentrations of Dinophysis cells at time 1 and time 2 are represented as $C_{1}$ and $C_{2}$, (cells $/ \mathrm{mL}$ ), respectively.

\subsection{Statistical Analysis}

Repeated Measures ANOVA (SigmaPlot v12.0, Systat Software Inc., London, UK) was used to analyze for differences in DSP and PTX2 toxin content, total toxin concentrations, and differences of toxin production rates between treatments or over time. Shapiro-Wilk test was used to test for normality. T-tests were used to analyze for any differences in growth rate and biomass of Dinophysis between treatments. Alpha was set at 0.05 for all analyses.

Author Contributions: Writing-original draft preparation, H.G. and J.L.S.; Writing-review and editing, J.L.S. and M.T.; Visualization, H.G.; Supervision, M.T.; Project administration, M.T. and X.A.; Funding acquisition, J.L.S. and M.T.

Funding: This research was supported by a National Key R\&D Program of China NO. 2016YFC1402104, Research on Public Welfare Technology Application Projects of Zhejiang Province, China NO. 2013C32040, Key Laboratory 
of Integrated Marine Monitoring and Applied Technologies for Harmful Algal Blooms, Ministry of Natural Resources of the People's Republic of China (MNR), MATHAB201803, the Laboratory of Marine Ecosystem and Biogeochemistry, MNR, LMEB201507, Natural Science Foundation of China (Grant No. 41306095) and Funding for Tang Scholar to M.T. Research completed in the USA was supported by NOAA Sea Grant Aquaculture Initiative NA14OAR4170093 and partial funding from the NOAA National Centers for Coastal Ocean Science ECOHAB Program grant number NA17NOS4780184 to J.L.S. This paper is contribution No. 3803 of the Virginia Institute of Marine Science, College of William \& Mary.

Acknowledgments: The authors would like to thank Lei Liu (National Marine Environmental Monitoring Center, China) and Caroline DeMent (VIMS) for their contributions to this work.

Conflicts of Interest: The authors declare no conflict of interest.

\section{References}

1. Hallegraeff, G.M. A review of harmful algal blooms and their apparent global increase. Phycologia 1993, 32, 79-99. [CrossRef]

2. Reguera, B.; Riobo, P.; Rodriguez, F.; Diaz, P.A.; Pizarro, G.; Paz, B.; Franco, J.M.; Blanco, J. Dinophysis toxins: Causative organisms, distribution and fate in shellfish. Mar. Drugs 2014, 12, 394-461. [CrossRef]

3. Zhou, J.; Fritz, L. Okadaic acid antibody localizes to chloroplasts in the DSP-toxin-producing dinoflagellates Prorocentrum lima and Prorocentrum maculosum. Phycologia 1994, 33, 455-461. [CrossRef]

4. Marasigan, A.N.; Sato, S.; Fukuyo, Y.; Kodama, M. Accumulation of a high level of diarrhetic shellfish toxins in the green mussel Perna viridis during a bloom of Dinophysis caudata and Dinophysis miles in Sapian Bay, Panay Island, the Philippines. Fish. Sci. 2001, 67, 994-996. [CrossRef]

5. Windust, A.J.; Wright, J.L.C.; McLachlan, J.L. The effects of the diarrhetic shellfish poisoning toxins, okadaic acid and dinophysistoxin-1, on the growth of microalgae. Mar. Biol. 1996, 126, 19-25. [CrossRef]

6. Windust, A.J.; Quilliam, M.A.; Wright, J.L.; McLachlan, J.L. Comparative toxicity of the diarrhetic shellfish poisons, okadaic acid, okadaic acid diol-ester and dinophysistoxin-4, to the diatom Thalassiosira weissflogii. Toxicon 1997, 35, 1591-1603. [CrossRef]

7. Miles, C.O.; Wilkins, A.L.; Munday, R.; Dines, M.H.; Hawkes, A.D.; Briggs, L.R.; Sandvik, M.; Jensen, D.J.; Cooney, J.M.; Holland, P.T.; et al. Isolation of pectenotoxin-2 from Dinophysis acuta and its conversion to pectenotoxin-2 seco acid, and preliminary assessment of their acute toxicities. Toxicon 2004, 43, 1-9. [CrossRef]

8. Ito, E.; Suzuki, T.; Oshima, Y.; Yasumoto, T. Studies of diarrhetic activity on pectenotoxin-6 in the mouse and rat. Toxicon 2008, 51, 707-716. [CrossRef]

9. Anonymous. Commission regulation (EC) No. 2074/2005 of the European parliament and of the council of 5 December 2005. Off. J. Eur. Commun. 2005, L338, 27-59.

10. Park, M.G.; Kim, S.; Kim, H.S.; Myung, G.; Kang, Y.G.; Yih, W. First successful culture of the marine dinoflagellate Dinophysis acuminata. Aquat. Microb. Ecol. 2006, 45, 101-106. [CrossRef]

11. Yih, W.; Kim, H.S.; Jeong, H.A.; Myung, G.; Kim, Y.G. Ingestion of cryptophyte cells by the marine photosynthetic ciliate Mesodinium rubrum. Aquat. Microb. Ecol. 2004, 36, 165-170. [CrossRef]

12. Takishita, K.; Koike, K.; Maruyama, T.; Ogata, T. Molecular evidence for plastid robbery (Kleptoplastidy) in Dinophysis, a dinoflagellate causing diarrhetic shellfish poisoning. Protist 2002, 153, 293-302. [CrossRef] [PubMed]

13. Hackett, J.D.; Maranda, L.; Yoon, H.S.; Bhattacharya, D. Phylogenetic evidence for the cryptophyte origin of the plastid of Dinophysis (Dinophysiales, Dinophyceae). J. Phycol. 2003, 39, 440-448. [CrossRef]

14. Janson, S.; Granéli, E. Genetic analysis of the psbA gene from single cells indicates a cryptomonad origin of the plastid in Dinophysis (Dinophyceae). Phycologia 2003, 42, 473-477. [CrossRef]

15. Johnson, M.D.; Oldach, D.; Delwiche, C.F.; Stoecker, D.K. Retention of transcriptionally active cryptophyte nuclei by the ciliate Myrionecta rubra. Nature 2007, 445, 426-428. [CrossRef] [PubMed]

16. Kim, G.H.; Han, J.H.; Kim, B. Cryptophyte gene regulation in the kleptoplastidic, karyokleptic ciliate Mesodinium rubrum. Harmful Algae 2016, 52, 23-33. [CrossRef] [PubMed]

17. Janson, S. Molecular evidence that plastids in the toxin-producing dinoflagellate genus Dinophysis originate from the free-living cryptophyte Teleaulax amphioxeia. Environ. Microbiol. 2004, 6, 1102-1106. [CrossRef] [PubMed] 
18. Hackett, J.D.; Tong, M.; Kulis, D.M.; Fux, E.; Hess, P.; Bire, R.; Anderson, D.M. DSP toxin production de novo in cultures of Dinophysis acuminata (Dinophyceae) from North America. Harmful Algae 2009, 8, 873-879. [CrossRef]

19. Kamiyama, T.; Suzuki, T. Production of dinophysistoxin-1 and pectenotoxin-2 by a culture of Dinophysis acuminata (Dinophyceae). Harmful Algae 2009, 8, 312-317. [CrossRef]

20. Kamiyama, T.; Nagai, S.; Suzuki, T.; Miyamura, K. Effect of temperature on production of okadaic acid, dinophysistoxin-1, and pectenotoxin-2 by Dinophysis acuminata in culture experiments. Aquat. Microb. Ecol. 2010, 60, 193-202. [CrossRef]

21. Nagai, S.; Suzuki, T.; Nishikawa, T.; Kamiyama, T. Differences in the production and excretion kinetics of okadaic acid, dinophysistoxin-1, and pectenotoxin-2 between cultures of Dinophysis acuminata and Dinophysis fortii isolated from western Japan. J. Phycol. 2011, 47, 1326-1337. [CrossRef] [PubMed]

22. Nielsen, L.T.; Krock, B.; Hansen, P.J. Effects of light and food availability on toxin production, growth and photosynthesis in Dinophysis acuminata. Mar. Ecol. Prog. Ser. 2012, 471, 37-50. [CrossRef]

23. Mafra, L.L.; dos Santos Tavares, C.P.; Schramm, M.A. Diarrheic toxins in field-sampled and cultivated Dinophysis spp. cells from southern Brazil. J. Appl. Phycol. 2014, 26, 1727-1739. [CrossRef]

24. Hattenrath-Lehmann, T.; Gobler, C.J. The contribution of inorganic and organic nutrients to the growth of a North American isolate of the mixotrophic dinoflagellate, Dinophysis acuminata. Limnol. Oceanogr. 2015, 60, 1588-1630. [CrossRef]

25. Tong, M.; Smith, J.L.; Richlen, M.; Steidinger, K.A.; Kulis, D.M.; Fux, E.; Anderson, D.M. Characterization and comparison of toxin-producing isolates of Dinophysis acuminata from New England and Canada. J. Phycol. 2015, 51, 66-81. [CrossRef] [PubMed]

26. Gao, H.; An, X.; Liu, L.; Zhang, K.; Zheng, D.; Tong, M. Characterization of Dinophysis acuminata from the Yellow Sea, China, and its response to different temperatures and Mesodinium prey. Oceanol. Hydrobiol. Stud. 2017, 46, 439-450. [CrossRef]

27. Nishitani, G.; Nagai, S.; Sakiyama, S.; Kamiyama, T. Successful cultivation of the toxic dinoflagellate Dinophysis caudata (Dinophyceae). Plankton Benthos Res. 2008, 3, 78-85. [CrossRef]

28. Nishitani, G.; Nagai, S.; Takano, Y.; Sakiyama, S.; Baba, K.; Kamiyama, T. Growth characteristics and phylogenetic analysis of the marine dinoflagellate Dinophysis infundibulus (Dinophyceae). Aquat. Microb. Ecol. 2008, 52, 209-221. [CrossRef]

29. Nielsen, L.T.; Krock, B.; Hansen, P.J. Production and excretion of okadaic acid, pectenotoxin-2 and a novel dinophysistoxin from the DSP-causing marine dinoflagellate Dinophysis acuta-Effects of light, food availability and growth phase. Harmful Algae 2013, 23, 34-45. [CrossRef]

30. Mafra, L.L., Jr.; Nagai, S.; Uchida, H.; Tavares, C.P.; Escobar, B.P.; Suzuki, T. Harmful effects of Dinophysis to the ciliate Mesodinium rubrum: Implications for prey capture. Harmful Algae 2016, 59, 82-90. [CrossRef]

31. Papiol, G.G.; Beuzenberg, V.; Selwood, A.I.; MacKenzie, L.; Packer, M.A. The use of a mucus trap by Dinophysis acuta for the capture of Mesodinium rubrum prey under culture conditions. Harmful Algae 2016, 58, 1-7. [CrossRef] [PubMed]

32. Maestrini, S.Y.; Berland, B.R.; Grzebyk, D.; Spano, A.M. Dinophysis spp cells concentrated from nature for experimental purposes, using size fractionation and reverse migration. Aquat. Microb. Ecol. 1995, 9, 177-182. [CrossRef]

33. Sampayo, T.J. Trying to cultivate Dinophysis spp. In Toxic Phytoplankton Blooms in the Sea; Smayda, T.J., Shimizu, Y., Eds.; Elsevier Science Publisher: New York, NY, USA, 1993; pp. 807-811. ISBN O-444-89719-4.

34. Hattenrath-Lehmann, T.K.; Marcoval, M.A.; Mittlesdorf, H.; Goleski, J.A.; Wang, Z.H.; Haynes, B.; Morton, S.L.; Gobler, C.J. Nitrogenous nutrients promote the growth and toxicity of Dinophysis acuminata during estuarine bloom events. PLoS ONE 2015, 10, e0124148. [CrossRef] [PubMed]

35. Tong, M.; Smith, J.L.; Kulis, D.M.; Anderson, D.M. Role of dissolved nitrate and phosphate in isolates of Mesodinium rubrum and toxin-producing Dinophysis acuminata. Aquat. Microb. Ecol. 2015, 75, 169-185. [CrossRef] [PubMed]

36. Seeyave, S.; Probyn, T.; Pitcher, G.; Lucas, M.; Purdie, D. Nitrogen nutrition in assemblages dominated by Pseudo-nitzschia spp., Alexandrium catenella and Dinophysis acuminata off the west coast of South Africa. Mar. Ecol. Prog. Ser. 2009, 379, 91-107. [CrossRef] 
37. Hattenrath-Lehmann, T.K.; Marcoval, M.A.; Berry, D.L.; Fire, S.; Wang, Z.; Morton, S.L.; Gobler, C.J. The emergence of Dinophysis acuminata blooms and DSP toxins in shellfish in New York waters. Harmful Algae 2013, 26, 33-44. [CrossRef]

38. Smith, J.L.; Tong, M.; Fux, E.; Anderson, D.M. Toxin production, retention, and extracellular release by Dinophysis acuminata during extended plateau phase and culture decline. Harmful Algae 2012, 19, 125-132. [CrossRef]

39. Kim, S.; Kang, Y.G.; Kim, H.S.; Yih, W.; Coats, D.W.; Park, M.G. Growth and grazing responses of the mixotrophic dinoflagellate Dinophysis acuminata as functions of light intensity and prey concentration. Aquat. Microb. Ecol. 2008, 51, 301-310. [CrossRef]

40. Riisgaard, K.; Hansen, P.J. Role of food uptake for photosynthesis, growth and survival of the mixotrophic dinoflagellate Dinophysis acuminata. Mar. Ecol. Prog. Ser. 2009, 381, 51-62. [CrossRef]

41. Tong, M.; Kulis, D.M.; Fux, E.; Smith, J.L.; Hess, P.; Zhou, Q.; Anderson, D.M. The effects of growth phase and light intensity on toxin production by Dinophysis acuminata from the northeastern United States. Harmful Algae 2011, 10, 254-264. [CrossRef]

42. Harred, L.B.; Campbell, L. Predicting harmful algal blooms: A case study with Dinophysis ovum in the Gulf of Mexico. J. Plankton Res. 2014, 36, 1434-1445. [CrossRef]

43. Anderson, D.M.; Kulis, D.M.; Doucette, G.J.; Gallagher, J.C.; Balech, E. Biogeography of toxic dinoflagellates in the genus Alexandrium from the northeastern United-States and Canada. Mar. Biol. 1994, 120, 467-478. [CrossRef]

44. Sagert, S.; Krause Jensen, D.; Henriksen, P.; Rieling, T.; Schubert, H. Integrated ecological assessment of Danish Baltic Sea coastal areas by means of phytoplankton and macrophytobenthos. Estuar. Coast. Shelf Sci. 2005, 63, 109-118. [CrossRef]

45. Smith, J.L.; Tong, M.; Kulis, D.; Anderson, D.M. Effect of ciliate strain, size, and nutritional content on the growth and toxicity of mixotrophic Dinophysis acuminata. Harmful Algae 2018, 78, 95-105. [CrossRef]

46. Haines, K.C.; Guillard, R.R. Growth of vitamin b12-requiring marine diatoms in mixed laboratory cultures with vitamin b12-producing marine bacteria. J. Phycol. 1974, 10, 245-252.

47. Azam, F. Microbial control of oceanic carbon flux: The plot thickens. Science 1998, 280, 694-696. [CrossRef]

48. Sakami, T.; Nakahara, H.; Chinain, M.; Ishida, Y. Effects of epiphytic bacteria on the growth of the toxic dinoflagellate Gambierdiscus toxicus (Dinophyceae). J. Exp. Mar. Biol. Ecol. 1999, 233, 231-246. [CrossRef]

49. Gao, H.; Hua, C.; Tong, M. Impact of Dinophysis acuminata Feeding Mesodinium rubrum on Nutrient Dynamics and Bacterial Composition in a Microcosm. Toxins 2018, 10, 443. [CrossRef]

50. Ojamäe, K.; Hansen, P.J.; Lips, I. Mass entrapment and lysis of Mesodinium rubrum cells in mucus threads observed in cultures with Dinophysis. Harmful Algae 2016, 55, 77-84. [CrossRef]

51. Nagai, S.; Nitshitani, G.; Tomaru, Y.; Sakiyama, S.; Kamiyama, T. Predation by the toxic dinoflagellate Dinophysis fortii on the ciliate Myrionecta rubra and observation of sequestration of ciliate chloroplasts. J. Phycol. 2008, 44, 909-922. [CrossRef]

52. García-Portela, M.; Reguera, B.; Sibat, M.; Altenburger, A.; Rodríguez, F.; Hess, P. Metabolomic Profiles of Dinophysis acuminata and Dinophysis acuta Using Non-Targeted High-Resolution Mass Spectrometry: Effect of Nutritional Status and Prey. Mar. Drugs 2018, 16, 143. [CrossRef]

53. Jiang, H.; Kulis, D.M.; Brosnahan, M.L.; Anderson, D.M. Behavioral and mechanistic characteristics of the predator-prey interaction between the dinoflagellate Dinophysis acuminata and the ciliate Mesodinium rubrum. Harmful Algae 2018, 77, 43-54. [CrossRef]

54. Tong, M.; Zhou, Q.; David, K.M.; Jiang, T.; Qi, Y.; Donald, A.M. Culture techniques and growth characteristics of Dinophysis acuminata and its prey. Chin. J. Oceanol. Limnol. 2010, 28, 1230-1239. [CrossRef]

55. Guillard, R.R.L. Division rates. In Handbook of Phycological Methods: Culture Methods and Growth Measurements; Stein, J.R., Ed.; Cambridge University Press: Cambridge, UK, 1973; pp. 289-312. ISBN 10: 0521200490.

56. Anderson, D.M.; Kulis, D.M.; Sullivan, J.J.; Hall, S.; Lee, C. Dynamics and physiology of saxitoxin production by the dinoflagellates Alexandrium spp. Mar. Biol. 1990, 104, 511-524. [CrossRef]

(C) 2019 by the authors. Licensee MDPI, Basel, Switzerland. This article is an open access article distributed under the terms and conditions of the Creative Commons Attribution (CC BY) license (http:/ / creativecommons.org/licenses/by/4.0/). 